\title{
PENGARUH DAMPAK APLIKASI, KEMUDAHAN INFORMASI, DAN KEMUDAHAN APLIKASI TERHADAP KEPUTUSAN PENGGUNAAN UANG ELEKTRONIK GOPAY DALAM BERTRANSAKSI DI UMKM CBD JAKARTA
}

\author{
Benedicta Evienia Prabawanti', Marsiana Luciana Sitanggang², Thia Margaretha \\ Tarigan $^{3}$ \\ Fakultas Ekonomi dan Bisnis, Universitas Katolik Indonesia Atma Jaya \\ Jl. Jend. Sudirman No.51, Karet Semanggi, Jakarta Selatan \\ Email Korespondensi: benedicta.ep@atmajaya.ac.id
}

\begin{abstract}
ABSTRAK
Artikel ini ingin melihat pengaruh dampak aplikasi, kemudahan informasi dan kemudahan aplikasi gopay dalam keputusan penggunaannya dalam bertransaksi. Gopay merupakan salah satu alat pembayaran berupa uang tapi jenisnya virtual. Artikel ini memuat hasil penelitian yang mengambil 100 responden, responden tersebut adalah pembeli makanan yang transaksi pembayarannya dilakukan menggunakan uang elektronik gopay. Dari hasil pengolahan data hasil kuesioner, ternyata dampak aplikasi dan kemudahan aplikasi mempunyai pengaruh signifikan terhadap keputusan masyarakat untuk menggunakan uang elektronik gopay, sdangkan kemudahan informasi tidak memiliki pengaruh signifikan terhadap keputusan penggunaan uang elektronik. kesimpulan ini dapat dilihat dari nilai t statistic dan $\mathrm{p}$ value yang dihasilkan dari pengolahan data menggunakan software pls untuk setiap hipotesis.
\end{abstract}

Kata Kunci: Aplikasi, keputusan pengguna, uang elektronik.

\begin{abstract}
This article wants to look at the effects of application impact, ease of information and convenience of gopay applications in their use transactions decisions. Gopay is one of the forms of payment in the form of money but a virtual type. This article contains the results of a study that took 100 respondents, these respondents are food buyers whose payment transactions are carried out using gopay electronic money. From the results of questionnaire data processing, it turns out the impact of application and ease of application has a significant influence on people's decisions to use electronic money gopay, whereas the ease of information has no significant effect on the decision to use electronic money. this conclusion can be seen from the $t$ value of statistics and $p$ value generated from data processing using pls software for each hypothesis.
\end{abstract}

Keywords: Aplication, User Decision, Electronic Money. 


\section{PENDAHULUAN}

Kehidupan perekonomian suatu negara tidak bisa terlepas dari peranan uang sebagai alat tukar atau alat pembayaran. Uang mendukung perekonomian suatu negara akan berjalan dengan baik sehingga tujuan bernegara dapat tercapai, yaitu mencapai masyarakat adil dan makmur. Dari bidang moneter, jumlah uang yang beredar di suatu negara harus dikelola dengan baik sesuai kebutuhan perekonomian.

Salah satu bentuk uang sebagai instrumen pembayaran yang sedang berkembang adalah uang elektronik. Pengertian uang elektronik menurut Peraturan Bank Indonesia Nomor 11/12/PBI/2009 adalah alat pembayaran yang diterbitkan atas dasar nilai uang yang disetor terlebih dahulu kepada penerbit. Uang elektronik digunakan sebagai alat pembayaran kepada pedagang yang bukan merupakan penerbit uang elektronik tersebut.

Nilai uang disimpan secara elektronik dalam suatu media server atau chip, serta dapat dipindahkan untuk kepentingan transaksi pembayaran dan/atau transfer dana. Nilai uang ini bukanlah merupakan simpanan sebagaimana dimaksud dalam undang-undang yang mengatur mengenai perbankan, sehingga tidak diberikan bunga dan tidak dijamin oleh Lembaga Penjamin Simpanan (LPS). Uang elektronik lebih merupakan pengalihan bentuk dari uang tunai. (Bank Indonesia, 2006).

Berbeda pada awal penerbitannya, uang elektronik saat ini tidak hanya diterbitkan dalam bentuk chip yang tertanam pada kartu atau media lainnya (chip based), namun juga telah diterbitkan dalam media lain yaitu suatu media yang saat digunakan untuk bertransaksi akan terkoneksi terlebih dahulu dengan server penerbit (server based). Begitu pula dari sisi penggunannya, hampir dari seluruh uang elektronik yang diterbitkan tidak lagi bersifat single purpose, namun juga sudah multi purpose, yang dalam penelitian kali ini diasumsikan bahwa uang elektronik tidak hanya digunakan untuk satu jenis pembayaran, namun juga dapat digunakan di banyak merchant berbeda yang menerapkan sistem pembayaran yang sama.

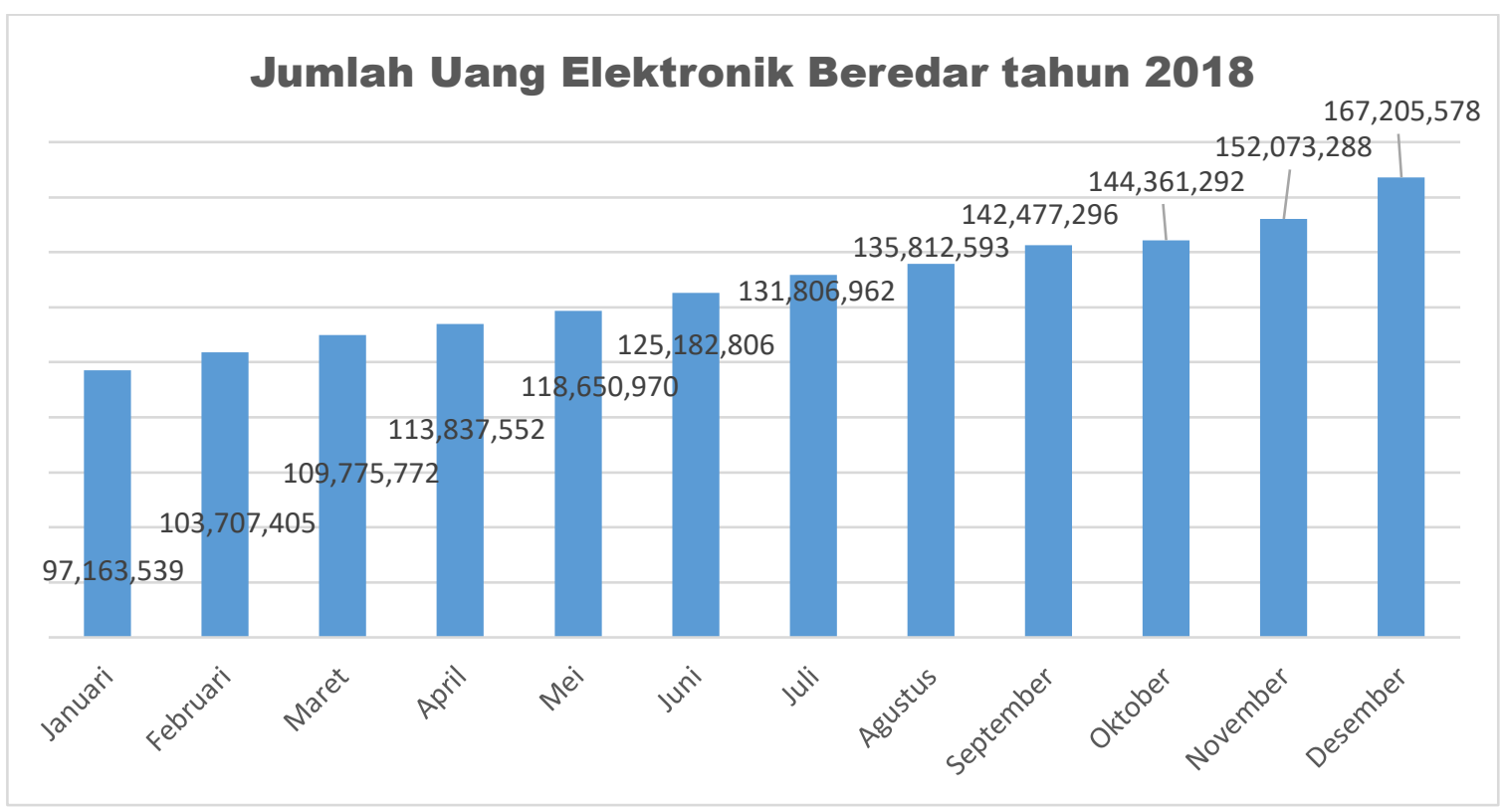

Gambar 1. Jumlah peredaran uang elektronik tahun 2018

Sumber Bank Indonesia, 2018 
Survei Pricewaterhouse Coopers (PwC) Indonesia menunjukkan 72\% responden yang merupakan banker eksekutif senior mengganggap uang elektronik Gopay sebagai pesaing yang patut diperhitungkan di Indonesia. Gopay banyak dipilih masyarakat karena beberapa alasan, yaitu adanya promo atau potongan harga, tidak perlu menyiapkan uang pas, dan mudah digunakan. Tahun 2018 beberapa warung makan atau kios pinggir jalan di Jakarta sudah menerima pembayaran non-tunai atau cashless melalui Gopay. Ini sejalan dengan tujuan perusahaan penerbit Gopay untuk merangkul lebih banyak lapisan masyarakat diantaranya pengusaha mikro seperti pedagang kaki lima dalam menggunakan uang elektronik untuk membantu semangat pemerintah menciptakan cashless society.

\section{Uang Elektronik}

Uang Elektronik (Electronic Money) didefinisikan sebagai alat pembayaran yang memenuhi unsur-unsur sebagai berikut: 1) Diterbitkan atas dasar nilai uang yang disetor terlebih dahulu oleh pemegang kepada penerbit; 2) Nilai uang disimpan secara elektronik dalam suatu media seperti server atau chip; 3) Digunakan sebagai alat pembayaran kepada pedagang yang bukan merupakan penerbit uang elektronik tersebut; dan 4) Nilai uang elektronik yang disetor oleh pemegang dan dikelola oleh penerbit bukan merupakan simpanan sebagaimana dimaksud dalam undang-undang yang mengatur mengenai perbankan.

Penyelenggaraan Uang Elektronik telah diatur dalam 1) Peraturan Bank Indonesia Nomor 11/12/PBI/2009 tanggal 13 April 2009 tentang Uang Elektronik (Electronic Money), 2) Surat Edaran Bank Indonesia No.11/11/DASP tanggal 13 April 2009 perihal Uang Elektronik (Electronic Money).

Pemahaman akan sistem atau cara kerja uang elektronik sangat diperlukan guna mendukung meningkatnya penggunaan uang elektronik di masyarakat. Masyarakat perlu mendapat pemahaman bahwa layanan uang elektronik dapat diperoleh dari agen layanan keuangan digital maupun akses pribadi melalui smartphone. Penggunaan uang elektronik yang ditujukan untuk memudahkan individu tentu harus memiliki keunggulan diantaranya nilai praktis yang selama ini digaungkan sebagai keunggulan uang elektronik.

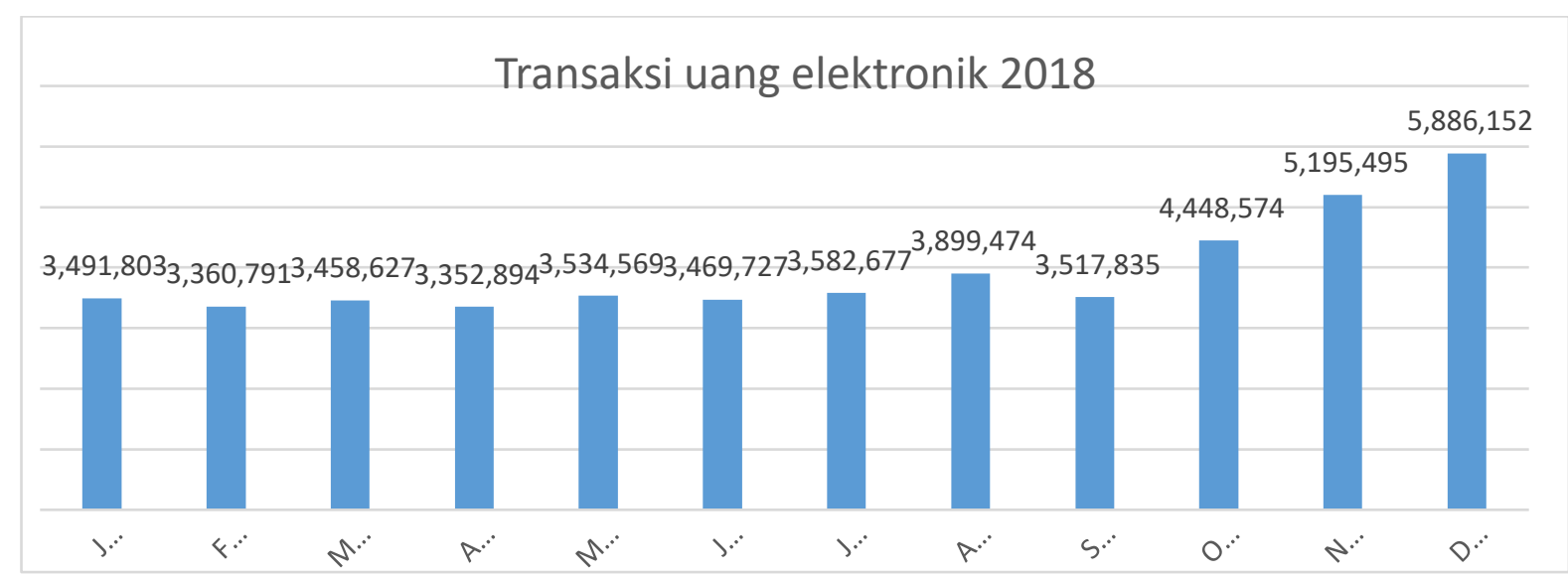

Gambar 2. Nominal Transaksi Uang Elektronik 2018 (dalam juta rupiah) Sumber Bank Indonesia, 2018 
Kemanfaatan uang elektronik dapat dilihat dari besaran nominal transaksi yang terjadi di Indonesia selama 2018 seperti pada gambar 2 di atas. Akibat kemanfaatan maka besaran nilai transaksi pun meningkat. Menurut Bank Indonesia, alat pembayaran non tunai memberikan manfaat kepada perekonomian Antara lain: 1) Tingkat kepuasan konsumen yang semakin bertambah dengan tidak perlu membawa banyak uang tunai, 2) Menekan biaya pengelolaan rupiah dan sah handling, 3) Peningkatan kecepatan dan transparansi transaksi, 4) Transaksi tercatat lebih lengkap sehingga perencanaan akan lebih akurat.

\section{Pengertian Konsumen}

Pengertian konsumen adalah setiap orang pemakai barang dan atau jasa yang tersedia dalam masyarakat, baik bagi kepentingan diri sendiri, keluarga, orang lain, maupun makhluk hidup lain dan tidak untuk diperdagangkan. Menurut pengertian Pasal 1 angka 2 UU PK, "Konsumen adalah setiap orang pemakai barang dan/atau jasa yang tersedia dalam masyarakat, baik bagi kepentingan diri sendiri, keluarga,, orang lain, maupun makhluk hidup lain dan tidak untuk diperdagangkan.

\section{Perilaku Konsumen}

Menurut Griffin dalam Sopiah dan Sangadji (2013:8), perilaku konsumen adalah semua kegiatan, tindakan, serta proses psikologi yang mendorong tindakan tersebut pada saat sebelum membeli, ketika membeli, menggunakan, menghabiskan produk dan jasa setelah melakukan hal-hal diatas atau kegiatan mengevaluasi.

Menurut Hasan (2013:161), perilaku konsumen adalah studi proses yang terlibat ketika individu atau kelompok memilih, membeli, menggunakan, atau mengatur produk, jasa, idea atau pengalaman untuk memuaskan kebutuhan dan keinginan konsumen. Menurut Schiffman dan Kanuk dalam Sumarwan dkk (2012:186) mendefinisikan perilaku konsumen sebagai tindakan yang langsung terlibat dalam mendapatkan, mengonsumsi dan menghabiskan produk atau jasa, termasuk proses keputusan yang mendahului dan mengikuti tindakan ini Menurut Kotler dan Keller (2009:166) Perilaku konsumen adalah studi tentang bagaimana individu, kelompok, dan organisasi memilih, membeli, menggunakan, dan bagaimana barang, jasa, ide, atau pengalaman untuk memuaskan kebutuhan dan keinginan mereka.

Menurut Engel et al dalam Sopiah dan Sangadji (2013:7), perilaku konsumen adalah tindakan yang langsung terlibat dalam pemerolehan, pengonsumsian, dan penghabisan produk atau jasa, termasuk proses yang mendahului dan menyusul tindakan tersebut. Perilaku konsumen disimpulkan sebagai hal berikut berdasarkan pada penelitian yang dilakukan oleh Sopiah dan Sangadji (2013:9): 1) Disiplin ilmu yang mempelajari perilaku individu, kelompok atau organisasi dan proses-proses yang digunakan konsumen untuk menyeleksi, menggunakan produk, pelayanan, pengalaman (ide) untuk memuaskan kebutuhan dan keinginan konsumen, dan dampak dari proses-proses tersebut pada konsumen dan masyarakat, 2) Tindakan yang dilakukan oleh konsumen guna mencapai dan memenuhi kebutuhannya baik dalam penggunaan, pengonsumsian, dan penghabisan barang dan jasa, termasuk proses keputusan yang mendahului dan yang menyusul, 3) Tindakan atau perilaku yang dilakukan konsumen yang dimulai dengan merasakan adanya kebutuhan dan keinginan, kemudian berusaha mendapatkan produk yang 
diinginkan,mengonsumsi produk tersebut, dan berakhir dengan tindakan-tindakan pasca pembelian, yaitu perasaan puas atau tidak puas.

\section{HIPOTESIS}

$\mathrm{H}_{1:}$ Dampak aplikasi secara positif berpengaruh terhadap keputusan penggunaan $\mathrm{H}_{2}$ : Kemudahan aplikasi secara positif berpengaruh terhadap keputusan penggunaan $\mathrm{H}_{3}$ : Kemudahan informasi secara positif berpengaruh terhadap keputusan penggunaan

\section{METODE PENELITIAN}

Penelitian yang digunakan untuk menghasilkan artikel ini ruang lingkupnya adalah masyarakat DKI Jakarta yang menggunakan uang elektronik "gopay" untuk membayar belanja atau konsumsi mereka khususnya di daerah Central Business District Jakarta. Penelitian dilakukan di wilayah tempat penjualan makanan UMKM daerah Sudirman, Kuningan, dan Menteng Jakarta. Pemilihan ketiga tempat tersebut dengan asumsi bahwa di tiga lokasi ini banyak pegawai yang berumur antara 25-40 tahun yang menjadi objek penelitian ini sebagai pembeli di tempat penjualan makanan UMKM dimana pembayaran menggunakan uang elektronik "gopay". Teknik yang diambil untuk penelitian ini adalah Teknik non probability sampling. Non probability sampling adalah teknik pengambilan sampling yang memberikan peluang yang sama bagi setiap unsur atau anggota populasi untuk dipilih menjadi anggota sampel. Dalam non probability sampling ini menggunakan stratified random sampling, yakni Teknik pengambilan sampel dengan memperhatikan suatu tingkatan pada elemen populasi.

Data yang digunakan dalam penelitian ini merupakan data primer, dimana data tersebut diperoleh dengan penyebaran kuesioner dan juga dilengkapi dengan data sekunder yang merupakan penelitian yang bersumber dari studi pustaka atau internet. Data primer yang diperoleh dari penyebaran kuesioner menggunakan skala likert dalam penyusunannya. Pengujian hipotesis dilakukan berdasarkan hasil pengujian Inner Model (model struktural) yang meliputi output r-square, koefisien parameter dan t-statistik. Untuk melihat suatu hipotesis dapat diterima atau ditolak diantaranya dengan memperhatikan nilai signifikansi antar konstrak, t-statistik dan p-value. Pengujian hipotesis penelitian dilakukan dengan bantuan software PLS. Nilai-nilai tersebut dapat dilihat dari hasil bootstrapping. Rules of thumb yang digunakan pada penelitian ini adalah $\mathrm{t}$-statistik > 1,96 dengan tingkat signifikansi p-value 5\% dan koefisien beta positif.

\section{HASIL DAN PEMBAHASAN}

Berdasarkan pengolahan data kuesioner menggunakan PLS, diperoleh data path coefficients sebagai berikut:

Tabel 1 Hasil Path Coefficients

\begin{tabular}{|c|c|c|c|c|r|}
\hline & $\begin{array}{c}\text { Original } \\
\text { Sample (O) }\end{array}$ & $\begin{array}{c}\text { Sample } \\
\text { Mean (M) }\end{array}$ & $\begin{array}{c}\text { Standard } \\
\text { Deviation } \\
\text { (STDEV) }\end{array}$ & $\begin{array}{c}\text { T Statistics } \\
(\mid \mathbf{O} / \mathbf{S T D E V})\end{array}$ & P Values \\
\hline DA -> KP & 0.278 & 0.277 & 0.106 & 2.629 & 0.009 \\
\hline KA -> KP & 0.202 & 0.199 & 0.094 & 2.145 & 0.032 \\
\hline KI -> KP & 0.079 & 0.085 & 0.106 & 0.753 & 0.452 \\
\hline
\end{tabular}


Dari tabel di atas, dapat dilihat bahwa untuk pengujian hipotesis pertama ingin menguji apakah dampak aplikasi secara positif berpengaruh terhadap keputusan penggunaan. Hasil pengujian menunjukkan nilai koefisien beta dampak aplikasi terhadap keputusan penggunaan sebesar 0,278 dan t-statistik sebesar 2,629. Dari hasil ini dinyatakan t-statistik signifikan karena $>1,96$ dengan p-value $<0,05$ sehingga hipotesis pertama diterima. Hal tersebut menyimpulkan bahwa dampak aplikasi memiliki pengaruh positif terhadap keputusan penggunaan.

Hipotesis kedua ingin menguji apakah kemudahan aplikasi secara positif berpengaruh terhadap keputusan penggunaan. Hasil pengujian menunjukkan nilai koefisien beta kmudahan aplikasi terhadap keputusan penggunaan sebesar 0,202 dan tstatistik sebesar 2,145. Dari hasil ini dinyatakan t-statistik signifikan karena > 1,96 dengan p-value $<0,05$ sehingga hipotesis kedua diterima. Hal tersebut menyimpulkan bahwa kemudahan aplikasi memiliki pengaruh positif terhadap keputusan penggunaan.

Hipotesis ketiga ingin menguji apakah kemudahan informasi secara positif berpengaruh terhadap keputusan penggunaan. Hasil pengujian menunjukkan nilai koefisien beta dampak aplikasi terhadap keputusan penggunaan sebesar 0,079 dan tstatistik sebesar 0,753. Dari hasil ini dinyatakan t-statistik tidak signifikan karena < 1,96 dengan p-value $>0,05$ sehingga hipotesis ketiga ditolak. Hal tersebut menyimpulkan bahwa dampak aplikasi tidak memiliki pengaruh positif terhadap keputusan penggunaan.

Tabel 2. Ringkasan Hasil Pengujian Hipotesis

\begin{tabular}{|c|c|c|c|}
\hline & Hipotesis & Hasil & Keterangan \\
\hline H1 & $\begin{array}{c}\text { dampak aplikasi secara positif } \\
\text { berpengaruh terhadap } \\
\text { keputusan penggunaan }\end{array}$ & $\begin{array}{c}\text { koefisien beta }= \\
0,278 \\
\text { t statistik }=2,629 \\
\mathrm{p} \text { value }=0,009\end{array}$ & diterima \\
\hline $\mathrm{H} 2$ & $\begin{array}{l}\text { kemudahan aplikasi secara } \\
\text { positif berpengaruh terhadap } \\
\text { keputusan penggunaan }\end{array}$ & $\begin{array}{l}\text { koefisien beta }= \\
0,202 \\
\text { t statistik }=2,145 \\
\mathrm{p} \text { value }=0,032\end{array}$ & diterima \\
\hline H3 & $\begin{array}{l}\text { kemudahan informasi secara } \\
\text { positif berpengaruh terhadap } \\
\text { keputusan penggunaan }\end{array}$ & $\begin{array}{c}\text { koefisien beta }= \\
0,079 \\
\text { t statistik }=0,753 \\
\text { p value }=0,452\end{array}$ & ditolak \\
\hline
\end{tabular}

Berdasarkan hasil pengujian hipotesis dapat disimpulkan bahwa dampak dari adanya aplikasi gopay di kalangan masyarakat DKI Jakarta berpengaruh terhadap keputusan mereka untuk menggunakan gopay dalam bertransaksi di tempat atau lokasi penjual makanan yang menerima pembayaran dalam bentuk uang elektronik gopay. Artinya aplikasi tersebut membuat gaya hidup masyarakat berubah dari penggunaan uang cash ke elektronik. Untuk kalangan masyarakat di umur 25-40 yang memang jadi sasaran di penelitian tersebut, gaya hidup dalam bertransaksi sudah sangat berubah, tingkat kenyamanan yang lebih "simple" sudah menjadi harapan mereka dengan teknologi yang sudah sangat memadai sekarang. Cukup dengan membawa "smartphone" maka semua transaksi jual beli bisa diselesaikan dengan mudah dan hemat waktu. 
Kemudahan aplikasi gopay juga ternyata membawa pengaruh yang signifikan untuk masyarakat memutuskan menggunakan uang elektronik gopay tersebut. Kemudahan disini lebih ke penggunaan fiturnya di "smartphone" masyarakat. Dari cara "install" sampai menggunakan menu-menu yang ada pada aplikasi tersebut. Bahasa, ukuran gambar dan huruf yang digunakan atau ditempatkan dalam aplikasi tersebut sangat membuat nyaman para pengguna. Masyarakat yang menjadi sampel penelitian ini ternyata tidak beranggapan bahwa kemudahan informasi yang diperoleh tentang gopay mempengaruhi mereka untuk memutuskan menggunakan uang elektronik gopay. Iklan yang berisi informasi tentang gopay memang sangat banyak ditemukan. Akan tetapi hal tersebut tidak berpengaruh terahdap masyarakat, karena uang elektronik jenis atau merek lain pun sudah cukup beragam. Persepsi tiap masyarakat untuk memilih adalah hal yang menjadi tolak ukur penggunaan aplikasi tersebut.

\section{DAFTAR PUSTAKA}

Bank Indonesia. (2018). http://www.bi.go.id

Beck, T., Demirgüç-Kunt, A., \& Honohan, P. (2009). Access to financial services: Measurement, impact, and policies. The World Bank Research Observer, 24(1), 119-145.

Hasan, A. S. MM,(2013). Marketing dan Kasus-Kasus Pilihan. Yogyakarta, CAPS (Center for Academic Publishing Service).

Kartono, K., Munthe, A. G., \& Witono, B. M. (1980). Pedagang Kaki Lima sebagai realita urbanisasi dalam rangka menuju Bandung kota indah. Universitas Katolik Parahyangan.

Lukman Ali, D. (2004). Kamus Besar Bahasa Indonesia. Jakarta: Balai Pustaka. M. Shiddiq, KH. Nation State dan Khilafah, 4.

Milne, A., \& Parboteeah, P. (2016). The business models and economics of peer-to-peer lending.

Parastiti, D. E., Mukhlis, I., \& Haryono, A. (2015). Analisis penggunaan uang elektronik pada mahasiswa fakultas ekonomi universitas negeri malang (studi kasus: uang elektronik brizzi). Jurnal Ekonomi Dan Studi Pembangunan, 7(1), 75-82.

Poerwadarminta, W. J. S. (1954). Kamus umum bahasa Indonesia. Perpustakaan Perguruan Kementerian PP dan K..

Sangadji, E. M., \& Sopiah. (2013). Consumer Behavior: Perilaku Konsumen dan Strategi Pemasaran Jilid 2. Jakarta: Erlangga.

Singh, S. (1999). Electronic money: understanding its use to increase the effectiveness of policy. Telecommunications Policy, 23(10-11), 753-773.

Sumarwan, U., Puspitawati, H., Hariadi, A., Ali, M. M., Gazali, M., Hartono, S., \& Farina, T. (2013). Riset Pemasaran dan Konsumen. Bogor: PT. 